\title{
Sofrimento nos enfermeiros em cuidados de saúde primários
}

\author{
Suffering in primary care nurses \\ Sufrimiento de los enfermeros de atención primaria de la salud
}

Luísa Maria Pires ${ }^{1}$

(i) https://orcid.org/0000-0002-3226-6239

Maria João Monteiro ${ }^{2}$

(D) https://orcid.org/0000-0003-0610-0670

José Jacinto Vasconcelos-Raposo ${ }^{2}$

(D) https://orcid.org/0000-0002-3456-9727

${ }^{1}$ Centro Hospitalar de Trás-os-Montes e

Alto Douro, Vila Real, Portugal

${ }^{2}$ Universidade de Trás-os-Montes e Alto Douro, Vila Real, Portugal
Autor de correspondência:

Luísa Maria Pires

Email: lpires.luisamaria@gmail.com
Recebido: 04.12.19

Aceite: 11.03 .20

\section{Resumo}

Enquadramento: $\mathrm{O}$ sofrimento nos enfermeiros advém da prestação de cuidados ao doente em sofrimento e de fatores relacionados com as condiçóes de trabalho. É uma experiência multidimensional que ocorre em situaçóes de perda, dano ou ameaça à integridade da pessoa.

Objetivo: Comparar as médias das dimensóes do sofrimento (Dor Emocional, Perda Relacional e Evitamento) em função das variáveis sociodemográficas e profissionais dos enfermeiros.

Metodologia: Estudo descritivo e transversal de natureza quantitativa. Amostra constituída por 100 enfermeiros. Foi aplicado um questionário de autopreenchimento e para avaliação do sofrimento a Caregiver Grief Scale.

Resultados: O sexo feminino com filhos, com companheiro, sem especialização em enfermagem e com mais tempo de serviço apresentou médias mais elevadas de sofrimento. No sexo masculino, as médias mais elevadas verificaram-se nos enfermeiros sem filhos, sem companheiro, com especialização em enfermagem e com mais tempo de serviço.

Conclusáo: Os enfermeiros apresentaram médias mais elevadas de sofrimento na dimensão Dor Emocional, seguida da Perda Relacional e do Evitamento, sendo maior a expressão do sofrimento no sexo feminino.

Palavras-chave: sofrimento psíquico; enfermeiros; cuidados de saúde primários

\section{Abstract}

Background: Suffering in nurses is associated with the delivery of care to patients in suffering and factors related to the working conditions. It is a multidimensional experience that occurs in situations of loss, damage, or threat to human integrity.

Objective: To compare the mean scores in the dimensions of suffering (Emotional Pain, Relational Loss, and Avoidance) based on the sociodemographic and professional variables of nurses.

Methodology: A descriptive and cross-sectional study with a quantitative approach was conducted with a sample of 100 nurses. A self-administered questionnaire was applied, as well as the Caregiver Grief Scale for assessing suffering.

Results: Women with children, with a partner, without specialization in nursing, and with more years of service had higher mean scores of suffering. In men, the highest mean scores were found in nurses without children, without a partner, with specialization in nursing, and with more years of service.

Conclusion: Nurses showed higher mean scores of suffering in the dimension of Emotional Pain, followed by Relational Loss, and Avoidance, and suffering was higher among women.

Keywords: mental suffering; nurses; primary health care

\section{Resumen}

Marco contextual: El sufrimiento de los enfermeros proviene de la prestación de cuidados al paciente que sufre y de factores relacionados con las condiciones de trabajo. Es una experiencia multidimensional que se produce en situaciones de pérdida, daño o amenaza a la integridad de la persona.

Objetivo: Comparar las medias de las dimensiones del sufrimiento (Dolor Emocional, Pérdida Relacional y Evitación), según las variables sociodemográficas y profesionales de los enfermeros.

Metodología: Estudio descriptivo y transversal de naturaleza cuantitativa. La muestra constó de 100 enfermeros. Se aplicó un cuestionario de autocumplimentado y, para evaluar el sufrimiento, se utilizó la Caregiver Grief Scale.

Resultados: El sexo femenino con hijos, con pareja, sin especialización de enfermería y con más tiempo de servicio presentó medias más elevadas de sufrimiento. En el sexo masculino, las medias más altas se encontraron en los enfermeros sin hijos, sin pareja, con una especialización en enfermería y con más tiempo de servicio.

Conclusión: Los enfermeros presentaron medias más altas de sufrimiento en la dimensión Dolor Emocional, seguido de Pérdida Relacional y Evitación, y la expresión del sufrimiento fue mayor en el sexo femenino.

Palabras clave: estrés psicológico; enfermeras; atención primaria de salud

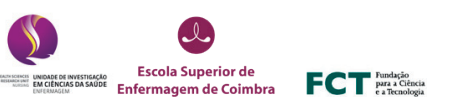

Como citar este artigo: Pires, L. M., Monteiro, M. J., \& Vasconcelos-Raposo, J. J. (2020). Sofrimento nos enfermeiros em cuidados de saúde primários. Revista de Enfermagem Referência, 5(1), e19096. doi: 10.12707/RIV19096. 


\section{Introdução}

A enfermagem comunitária e de saúde pública tem como foco a pessoa inserida na comunidade, ou seja, os enfermeiros em cuidados de saúde primários (CSP) cuidam de pessoas, famílias e grupos, no centro de saúde, no domicílio, ou em organizaçóes comunitárias, acompanhando-os ao longo do ciclo de vida, próximos dos seus anseios e problemas. É ainda responsável por diversas atividades de promoção da saúde e prevenção da doença numa área geográfica, bem como pela identificação de necessidades e articulação de cuidados com outros profissionais de saúde e instituiçóes com vista à sua continuidade e complementaridade (Regulamento no 128/2011, de 18 de fevereiro). A profissão de enfermagem assenta em valores éticos e no compromisso do enfermeiro em ajudar aqueles que estáo ao seu cuidado, caracterizando-se pela complexidade do cuidado contínuo e pela proximidade na relaçâo com o doente, família e restantes membros da equipa de saúde (Barlem \& Ramos, 2015). É uma profissão desgastante, com um ritmo de trabalho bastante intenso, que implica interagir, diariamente, com a pessoa em situação de dor e sofrimento, com outros profissionais e instituições, realizar todas as tarefas planeadas com iniciativa, rapidez e livre de qualquer erro. A alienação, a impossibilidade de agir com criatividade na relaçáo estabelecida com o doente e os limites colocados pela organização do trabalho ao uso do seu saber, surgem, muitas vezes, como fatores desencadeantes de sofrimento e desgaste. Devido à sobrecarga e ao stress enfrentado, a qualidade deste relacionamento pode estar comprometida, interferindo na qualidade dos cuidados prestados (Schaefer, 2017). Vários estudos associam sintomas físicos, emocionais e comportamentais, tais como cefaleias, fadiga, depressão, dores musculares, insónias, absentismo, automedicaçáo, fenómenos de stress e burnout, aos profissionais de saúde (Adwan, 2014), nomeadamente aos enfermeiros. Os enfermeiros ao proporcionarem os cuidados ao doente, promovem o seu bem-estar físico, psicológico e social e têm, simultaneamente, de adotar uma postura que extravasa as suas competências técnicas, ou seja, auxiliar o doente a superar o seu sofrimento. $\mathrm{O}$ ato de cuidar exige do cuidador investimento afetivo, daí ser natural o sofrer com a dor do doente. Neste processo que é, por natureza, interativo, aquando da valorização do exercício das funçóes destes profissionais, importa compreender como e qual o impacto que a exposição continuada ao sofrimento dos outros pode ter na saúde e bem-estar psicológico do enfermeiro. A qualidade de vida e as consequências biopsicossociais da tarefa de cuidar de outras pessoas têm sido objeto de uma ampla discussáo na literatura. A maioria da investigação tem privilegiado o estudo deste fenómeno em doentes ou cuidadores informais (Ramos, Barth, Schneider, Cabral, \& Reinaldo, 2016), sendo escassos os estudos que se debruçam sobre os profissionais de saúde que diariamente lidam com o sofrimento e até perda de vida daqueles que cuidam. Os enfermeiros, pela natureza dos cuidados que prestam e pela proximidade na relação terapêutica com o doente/família, são confrontados no quotidiano da sua prática com o sofrimento daqueles que cuidam e com o seu próprio sofrimento. Deste modo, parece consensual a necessidade de desenvolver estudos que visem compreender este fenómeno em profissionais de enfermagem, a fim de prevenir e atenuar o seu impacto e consciencializar as entidades de saúde para a implementação de medidas ou políticas que visem diminuir o sofrimento e a sobrecarga (Barlem \& Ramos, 2015; McCarthy \& Gastmans, 2015; Ramos et al., 2016). Assim, o objetivo deste estudo é comparar as médias das dimensóes do sofrimento (Dor Emocional, Perda Relacional e Evitamento) em função das variáveis sociodemográficas e profissionais dos enfermeiros.

\section{Enquadramento}

$\mathrm{O}$ ato de cuidar constitui a essência da praxis da enfermagem, pois é através do cuidar que o enfermeiro compreende a experiência do sofrimento do doente e da família na dimensão biopsicossocial e espiritual sem descurar que cuidar é um ato que requer conhecimento, responsabilidade e afetividade entre quem cuida e quem é cuidado (Coelho \& Ferreira, 2015). De acordo com Feneli, Gonçalves, e Azevedo dos Santos, "a dor e o sofrimento são experiências únicas, próprias, intransferíveis, difíceis, que ferem profundamente; experiências que podem ser consideradas de desprazer", (2006, p. 3). No caso dos enfermeiros, a prática profissional caracteriza-se por colocarem ao serviço dos doentes todo o seu saber e habilidades para lhes restituir a saúde. Da esperança frustrada resulta o sofrimento. No entanto, importa ter presente que o sofrimento é mediado por variáveis que influenciam o dia-a-dia dos profissionais, nomeadamente os aspetos socioculturais, económicos, obrigaçōes familiares, histórico de vivência do profissional com os elementos geradores do sofrimento, assim como outros de ordem psíquica e espiritual (Feneli et al., 2006).

De acordo com Viana (2014), o sofrimento é um fenómeno complexo e difícil de expressar por palavras. É subjetivo, individual, intocável, invisível, intransmissível e inerente à dimensão psicológica do ser humano. Krikorian, Limonero, Román, Vargas, e Palacio (2014), falam do sofrimento como uma experiência multidimensional e dinâmica de stress severo, que ocorre perante eventos de ameaça à integridade da pessoa no seu todo, podendo conduzir à exaustáo. Resulta da experiência pessoal e pode ser vivenciado em diversas situaçóes em que se verifique perda, dano ou ameaça à integridade da pessoa. Não é possível viver uma vida sem sofrimento, pois de uma forma ou de outra, com maior ou menor intensidade, todas as pessoas o vivenciam, sendo, por isso, um fenómeno universal, biopsicossocial e espiritual, que está presente em todos os contextos associados à doença (Viana, 2014), tendo repercussóes para os profissionais de saúde. É acompanhado por emoçôes intensas entre as quais se destacam a tristeza, a angústia, o medo, o abandono e o desespero (Adwan, 2014). A sua intensidade "varia conforme a cultura, os valores, o mundo afetivo e social, os sentimentos de pertencimento, as ideias e as escolhas do próprio sujeito" (Coelho \& Ferreira, 2015, p. 347). Os fatores que determinam o sofrimento podem estar 
relacionadas com os ambientes de trabalho em saúde e a forma como estão organizados (Caçador, Ramos, \& Brito, 2017), com situações clínicas, nomeadamente os tratamentos em fim de vida e o controlo da dor, condições de trabalho difíceis, recursos limitados, condiçôes estruturais, fontes morais, prática de horários rígidos, falta de profissionais e, consequentemente, excessiva carga de trabalho (McCarthy \& Gastmans, 2015). A falta de preparação dos enfermeiros em lidar com o sofrimento e a morte induz sentimentos que potenciam o sofrimento (Viana, 2014). O sofrimento ou a angústia moral é um problema grave que afeta os enfermeiros em diferentes contextos de trabalho e "pode gerar sentimentos de insatisfação, sintomas físicos e emocionais, cansaço, rotatividade de pessoal e, até mesmo, abandono da profissão, podendo levar a um impacto importante na qualidade dos cuidados em saúde" (Schaefer \& Vieira, 2015, p. 564). Segundo as autoras citadas, mesmo enfermeiros experientes continuam a vivenciar o sofrimento, o que demonstra a necessidade de fortalecer a capacidade destes profissionais para lidar de forma positiva com a perda ou sofrimento. Os enfermeiros sentem necessidade de suporte e apoio psicológico para enfrentar o sofrimento humano e para lidar com as emoçôes do doente e as suas próprias emoçóes, com o intuito de ajudar na gestão das mesmas, de forma a preservar o seu equilíbrio emocional e, assim, prestarem cuidados de enfermagem de qualidade (Coelho, Brito, \& Barbosa, 2017).

\section{Questáo de investigaçáo}

Qual a relação entre as dimensões do sofrimento (Dor Emocional, Perda Relacional e Evitamento) e as variáveis sociodemográficas e profissionais dos enfermeiros?

\section{Metodologia}

Estudo descritivo e transversal, de natureza quantitativa. A população-alvo foi a totalidade de enfermeiros que exercem a atividade profissional em CSP num Agrupamento de Centros de Saúde (ACeS) do interior Norte de Portugal, perfazendo um total de 111 enfermeiros, de acordo com informação do Diretor Executivo do ACeS referido. Este, através de e-mail, solicitou a participação de todos os profissionais no estudo, sendo que 11 enfermeiros não devolveram o questionário no prazo estabelecido, o que foi interpretado como recusa em participar. Os questionários foram disponibilizados num envelope aberto ao enfermeiro responsável por cada unidade funcional que os distribuiu pelos enfermeiros das referidas unidades e procedeu à sua recolha num envelope fechado. Os participantes preencheram o questionário durante o período laboral ou de descanso, no momento que consideraram mais pertinente. $\mathrm{O}$ investigador não esteve presente $\mathrm{du}$ rante a recolha de dados e não teve qualquer contacto com os participantes. Neste estudo participaram 100 enfermeiros, o que corresponde a 90,09\% da população.
O instrumento de recolha de dados foi um questionário, estruturado em duas partes: na primeira parte consta a caracterização sociodemográfica e profissional da amostra em estudo e na segunda consta a Caregiver Grief Scale (CGS) para avaliar o sofrimento dos enfermeiros, adaptada e validada para os enfermeiros portugueses em CSP por Vasconcelos-Raposo, Pires, Teixeira, \& Monteiro (no prelo). A escala é constituída por 11 itens que avaliam três dimensōes do sofrimento do cuidador: Dor Emocional (itens 1 a 3), Perda Relacional (itens 4 a 8) e Evitamento (itens 9 a 11). A dimensão Dor Emocional (DE) diz respeito à experiência de sofrimento e outras emoçóes desagradáveis, vivenciadas no presente, relacionadas com a perda de alguém. A dimensão Perda Relacional (PR) refere-se às perdas relativas ao relacionamento e experiências partilhadas com a pessoa cuidada quando esta ainda era saudável. No que respeita à dimensão Evitamento (EV), refere-se ao comportamento da pessoa com o objetivo de se proteger da dor psicológica, tal como expressa nas emoçōes geradas nos contextos e relacionamentos psicossociais, que no caso dos enfermeiros está diretamente relacionada com o seu envolvimento emocional com os doentes. A resposta aos itens que integram cada uma das dimensões é feita numa escala do tipo Likert que varia entre: 1 - discordo totalmente; 2 - discordo; 3 - concordo moderadamente; 4 concordo; e 5 - concordo totalmente (Meichsner, Schinköthe, \& Wilz, 2016). A variável dependente é o sofrimento nas diferentes dimensóes (DE, PR e EV) e as variáveis independentes são as características sociodemográficas e profissionais. A recolha de dados decorreu entre fevereiro e março de 2018. Os dados obtidos foram inseridos e analisados numa base de dados no software IBM SPSS Statistics, versão 24.0 , tendo por base uma matriz dos dados previamente codificados para permitir a sua análise estatística. Recorreu-se à estatística descritiva, e por se tratar de uma amostra representativa da população em estudo $(90,09 \%)$ não se justificou qualquer tipo de análise inferencial. $\mathrm{Na}$ estatística descritiva, procedemos ao cálculo das frequências absolutas e frequências relativas para todas as variáveis, bem como à determinação das médias para cada dimensão do sofrimento (DE, PR e EV). O estudo obteve parecer favorável da Comissão de Ética para a Saúde da Administração Regional de Saúde Norte e do Diretor Executivo do ACeS, conforme parecer $n^{\circ}$ 2/2018 sobre o estudo T840. Foram respeitados os direitos fundamentais enunciados pela Declaração de Helsínquia e pelo Código de Ética de Nuremberg.

\section{Resultados}

Da caracterização da amostra é de referir que a idade mínima dos participantes é de 33 anos e a idade máxima é de 63 anos, sendo a média de 43,9 anos (desvio-padrão de 7,45$)$. Verifica-se uma predominância do sexo feminino em conformidade com a realidade da profissão de enfermagem. Os restantes elementos que caracterizam a amostra são apresentados na Tabela 1. 
Tabela 1

Caracterização sociodemográfica e profissional dos participantes

\begin{tabular}{|c|c|c|c|}
\hline & & $N(100)$ & $\%(100)$ \\
\hline \multirow{2}{*}{ Sexo } & Masculino & 10 & 10,0 \\
\hline & Feminino & 90 & 90,0 \\
\hline \multirow{2}{*}{ Estado civil } & Com companheiro & 81 & 81,0 \\
\hline & Sem companheiro & 19 & 19,0 \\
\hline \multirow{2}{*}{ Existência de filhos } & Sim & 81 & 81,0 \\
\hline & Não & 19 & 19,0 \\
\hline \multirow{2}{*}{ Especializaçáo em enfermagem } & Sim & 47 & 47,0 \\
\hline & Não & 53 & 53,0 \\
\hline \multirow{3}{*}{ Tempo de serviço } & $<11$ anos & 20 & 20,0 \\
\hline & $11-17$ anos & 50 & 50,0 \\
\hline & $>17$ anos & 30 & 30,0 \\
\hline \multirow{3}{*}{ Unidade funcional de prestaçáo de cuidados } & UCC & 37 & 37,0 \\
\hline & USF & 35 & 35,0 \\
\hline & UCSP & 28 & 28,0 \\
\hline \multirow{3}{*}{ Tipo de horário } & Jornada contínua & 88 & 88,0 \\
\hline & Horário rígido & 8 & 8,0 \\
\hline & Horário flexível & 4 & 4,0 \\
\hline \multirow{2}{*}{ Carga horária semanal } & 35 horas & 98 & 98,0 \\
\hline & 40 horas & 2 & 2,0 \\
\hline \multirow{5}{*}{$\begin{array}{l}\text { Frequência de jornadas contínuas com menos elementos } \\
\text { que o inicialmente planeado }\end{array}$} & Nunca & 5 & 5,0 \\
\hline & Raramente & 27 & 27,0 \\
\hline & Às vezes & 46 & 46,0 \\
\hline & Frequentemente & 18 & 18,0 \\
\hline & Muito frequentemente & 4 & 4,0 \\
\hline \multirow{5}{*}{$\begin{array}{l}\text { Frequência de cuidados a pessoas em fase terminal/em } \\
\text { cuidados paliativos }\end{array}$} & Nunca & 7 & 7,0 \\
\hline & Raramente & 28 & 28,0 \\
\hline & Às vezes & 38 & 38,0 \\
\hline & Frequentemente & 24 & 24,0 \\
\hline & Muito frequentemente & 3 & 3,0 \\
\hline \multirow{5}{*}{$\begin{array}{l}\text { Frequência de contacto com situaçóes de urgência/emer- } \\
\text { gência }\end{array}$} & Nunca & 4 & 4,0 \\
\hline & Raramente & 45 & 45,0 \\
\hline & Às vezes & 41 & 41,0 \\
\hline & Frequentemente & 10 & 10,0 \\
\hline & Muito frequentemente & 0 & 0,0 \\
\hline \multirow{5}{*}{$\begin{array}{l}\text { Frequência de prestaçáo de cuidados a pessoas em sofri- } \\
\text { mento }\end{array}$} & Nunca & 3 & 3,0 \\
\hline & Raramente & 11 & 11,0 \\
\hline & Às vezes & 27 & 27,0 \\
\hline & Frequentemente & 47 & 47,0 \\
\hline & Muito frequentemente & 12 & 12,0 \\
\hline \multirow{5}{*}{$\begin{array}{l}\text { Frequência de contacto com a morte de pessoas que esti- } \\
\text { veram ao seu cuidado }\end{array}$} & Nunca & 6 & 6,0 \\
\hline & Raramente & 23 & 23,0 \\
\hline & Às vezes & 36 & 36,0 \\
\hline & Frequentemente & 32 & 32,0 \\
\hline & Muito frequentemente & 3 & 3,0 \\
\hline \multirow{5}{*}{$\begin{array}{l}\text { Frequência com que transmite a informaçáo da morte da } \\
\text { pessoa à família/cuidador }\end{array}$} & Nunca & 52 & 52,0 \\
\hline & Raramente & 39 & 39,0 \\
\hline & Às vezes & 6 & 6,0 \\
\hline & Frequentemente & 3 & 3,0 \\
\hline & Muito frequentemente & 0 & 0,0 \\
\hline \multirow{2}{*}{ Cuidador informal } & Sim & 36 & 36,0 \\
\hline & Não & 64 & 64,0 \\
\hline \multirow{4}{*}{ Motivo para ser cuidador informal } & Opção pessoal & 22 & 61,1 \\
\hline & Decisão familiar & 11 & 30,56 \\
\hline & Recompensa monetária & 0 & 0,0 \\
\hline & Satisfação pessoal/Solidariedade & 3 & 8,33 \\
\hline
\end{tabular}

Nota UCC = Unidade de Cuidados na Comunidade; USF = Unidade de Saúde Familiar; UCSP = Unidade de Cuidados de Saúde Personalizados. 
Os profissionais de enfermagem do sexo feminino apresentam médias de sofrimento mais elevadas em quase todas as dimensões do sofrimento, comparativamente com o sexo masculino. O sexo feminino com filhos apresenta médias mais elevadas em todas as dimensões do sofrimento comparativamente com os enfermeiros sem filhos do mesmo sexo. Relativamente ao estado civil, os enfermeiros do sexo masculino sem companheiro apresentam médias mais elevadas nas dimensóes DE e PR, enquanto os enfermeiros do sexo feminino sem companheiro apresentam médias superiores apenas na dimensão DE (Tabela 2).

Tabela 2

Comparação das médias das dimensóes do sofrimento em função das variáveis sociodemográficas (sexo, estado civil e existência de filhos)

\begin{tabular}{|c|c|c|c|c|c|}
\hline \multicolumn{3}{|c|}{ Dimensóes do sofrimento } & \multirow{2}{*}{$\begin{array}{c}\text { Dor Emocional } \\
7,57\end{array}$} & \multirow{2}{*}{$\frac{\text { Perda Relacional }}{12,14}$} & \multirow{2}{*}{$\frac{\text { Evitamento }}{6,57}$} \\
\hline \multirow{8}{*}{$\begin{array}{c}\text { Variáveis } \\
\text { sociodemográficas }\end{array}$} & \multirow{4}{*}{ Sexo masculino } & Com filhos & & & \\
\hline & & Sem filhos & 8,33 & 14,33 & 6,00 \\
\hline & & Com companheiro & 7,44 & 12,33 & 6,44 \\
\hline & & Sem companheiro & 11,00 & 17,00 & 6,00 \\
\hline & \multirow{4}{*}{ Sexo feminino } & Com filhos & 9,82 & 15,36 & 7,94 \\
\hline & & Sem filhos & 9,56 & 13,81 & 7,31 \\
\hline & & Com companheiro & 9,68 & 15,19 & 7,90 \\
\hline & & Sem companheiro & 10,16 & 14,66 & 7,55 \\
\hline
\end{tabular}

Os enfermeiros do sexo masculino que possuem especialização em enfermagem apresentam médias mais elevadas em todas as dimensóes do sofrimento. Pelo contrário, os enfermeiros do sexo feminino com especialização em enfermagem, apresentam médias mais baixas em todas as dimensôes do sofrimento. Quanto ao tempo de serviço e de um modo geral, os profissionais do sexo feminino e com mais tempo de serviço apresentam médias mais elevadas de sofrimento em quase todas as dimensóes (Tabela 3).

Tabela 3

Comparação das médias das dimensôes do sofrimento em função das variáveis profissionais (especialização em enfermagem e tempo de serviço)

\begin{tabular}{|c|c|c|c|c|c|}
\hline \multicolumn{3}{|c|}{ Dimensóes do sofrimento } & \multirow{2}{*}{$\begin{array}{c}\text { Dor Emocional } \\
8,25 \\
\end{array}$} & \multirow{2}{*}{$\begin{array}{c}\text { Perda Relacional } \\
13,12\end{array}$} & \multirow{2}{*}{$\frac{\text { Evitamento }}{7,00}$} \\
\hline \multirow{12}{*}{$\begin{array}{l}\text { Variáveis } \\
\text { profissionais }\end{array}$} & \multirow{6}{*}{ Sexo masculino } & Com especialização & & & \\
\hline & & Sem especialização & 6,00 & 11,50 & 4,00 \\
\hline & & Tempo de serviço: & & & \\
\hline & & Até 11 anos de serviço & 9,00 & 16,00 & 5,50 \\
\hline & & 11-17 anos de serviço & 8,00 & 10,66 & 6,33 \\
\hline & & $>17$ anos de serviço & 6,00 & 16,00 & 7,55 \\
\hline & \multirow{6}{*}{ Sexo feminino } & Com especialização & 9,23 & 14,07 & 7,56 \\
\hline & & Sem especialização & 10,19 & 15,86 & 8,03 \\
\hline & & Tempo de serviço: & & & \\
\hline & & Até 11 anos de serviço & 8,77 & 15,66 & 7,11 \\
\hline & & 11-17 anos de serviço & 9,29 & 14,73 & 7,59 \\
\hline & & $>17$ anos de serviço & 10,31 & 15,23 & 8,19 \\
\hline
\end{tabular}

Verifica-se que os enfermeiros que muito frequentemente ou frequentemente trabalham em jornada contínua com menos elementos na equipa de enfermagem que o inicialmente planeado, e que muito frequentemente prestam cuidados a pessoas em fase terminal/cuidados paliativos, apresentam médias mais elevadas nas dimensóes DE e PR, respetivamente, enquanto que aqueles que nunca prestam cuidados nas situações acima referidas apresentam médias mais elevadas na dimensão EV. Os enfermeiros que nunca têm contacto com situaçóes de urgência/emergência, com a prestação de cuidados a pessoas em sofrimento e com a morte de pessoas que estiveram ao seu cuidado são os que apresentam médias mais elevadas em todas as dimensóes do sofrimento. Os enfermeiros que frequentemente comunicam a morte à família/cuidador apresentam médias mais elevadas em todas as dimensões do sofrimento (Tabela 4). 
Tabela 4

Comparação das médias das dimensöes do sofrimento em função de variáveis profissionais (frequência de jornada contínua, cuidados à pessoa em sofrimento e fase terminal, contacto com situaçôes de urgência, com a morte e transmissão da informação da morte)

\begin{tabular}{|c|c|c|c|c|c|}
\hline & \multicolumn{2}{|c|}{ Dimensóes do sofrimento } & \multirow{2}{*}{$\begin{array}{c}\begin{array}{c}\text { Dor } \\
\text { Emocional }\end{array} \\
9,60\end{array}$} & \multirow{2}{*}{$\begin{array}{c}\begin{array}{c}\text { Perda } \\
\text { Relacional }\end{array} \\
14,00\end{array}$} & \multirow{2}{*}{$\begin{array}{c}\text { Evitamento } \\
8,80\end{array}$} \\
\hline & & Nunca & & & \\
\hline & Frequência de jornada contínua com & Raramente & 8,40 & 13,44 & 7,03 \\
\hline & menos elementos que o inicialmente & Às vezes & 9,97 & 15,17 & 7,56 \\
\hline & planeado & Frequentemente & 10,05 & 16,94 & 8,44 \\
\hline & & Muito frequentemente & 10,75 & 12,50 & 8,75 \\
\hline & & Nunca & 9,42 & 11,85 & 8,14 \\
\hline & & Raramente & 9,89 & 14,85 & 7,82 \\
\hline & $\begin{array}{l}\text { Frequencia de cuidados a pessoas em } \\
\text { fase terminal/em cuidados paliativos }\end{array}$ & Às vezes & 9,92 & 15,21 & 8,07 \\
\hline & & Frequentemente & 8,54 & 14,95 & 7,12 \\
\hline & & Muito frequentemente & 11,00 & 16,66 & 5,00 \\
\hline & & Nunca & 10,75 & 15,00 & 8,75 \\
\hline & & Raramente & 9,73 & 14,71 & 7,24 \\
\hline & Frequência de contacto com situa- & Às vezes & 9,26 & 15,02 & 8,02 \\
\hline & & Frequentemente & 9,70 & 14,80 & 7,90 \\
\hline \multirow{16}{*}{$\begin{array}{l}\text { Variáveis } \\
\text { profissionais }\end{array}$} & & Muito frequentemente & --- & --- & --- \\
\hline & & Nunca & 11,33 & 15,00 & 9,66 \\
\hline & & Raramente & 10,18 & 14,36 & 8,18 \\
\hline & $\begin{array}{l}\text { Frequência de prestação de cuidados } \\
\text { a pessoas em sofrimento }\end{array}$ & Às vezes & 9,37 & 14,14 & 7,37 \\
\hline & & Frequentemente & 9,46 & 15,27 & 7,80 \\
\hline & & Muito frequentemente & 9,50 & 15,15 & 7,00 \\
\hline & & Nunca & 10,16 & 14,50 & 7,16 \\
\hline & Frequência de contacto com a morte & Raramente & 10,13 & 14,56 & 7,60 \\
\hline & de pessoas que estiveram ao seu & Às vezes & 9,36 & 14,72 & 7,13 \\
\hline & cuidado & Frequentemente & 9,28 & 15,25 & 8,53 \\
\hline & & Muito frequentemente & 10,00 & 15,33 & 7,00 \\
\hline & & Nunca & 9,76 & 14,98 & 7,48 \\
\hline & Frequência com que transmite a & Raramente & 9,10 & 14,76 & 7,41 \\
\hline & informação da morte da pessoa à & Às vezes & 10,16 & 13,33 & 9,83 \\
\hline & família/cuidador & Frequentemente & 11,33 & 17,00 & 10,66 \\
\hline & & Muito frequentemente & --- & --- & --- \\
\hline
\end{tabular}

A maioria dos enfermeiros dos CSP (98\%) tem uma carga horária semanal de 35 horas. São estes profissionais, os que possuem um horário rígido e os que prestam cuidados na Unidade de Cuidados de Saúde Personalizados (UCSP) que apresentam médias mais elevadas em todas as dimensões de sofrimento. Os enfermeiros que cumulativamente desempenham o papel de cuidadores informais no seio familiar, apresentam médias mais elevadas nas dimensões DE e PR. De igual modo, os enfermeiros que desempenham este papel por opção pessoal apresentam médias mais elevadas na dimensão DE (Tabela 5). 
Pires, L. M. et al.

Tabela 5

Comparação das médias das dimensöes do sofrimento em função das variáveis profissionais (Unidade funcional de prestação de cuidados, tipo de horário realizado, carga horária semanal, cuidador informal e motivo para tal)

\begin{tabular}{|c|c|c|c|c|c|}
\hline \multicolumn{3}{|c|}{ Dimensóes do sofrimento } & \multirow{2}{*}{$\begin{array}{c}\begin{array}{c}\text { Dor } \\
\text { Emocional }\end{array} \\
9,40\end{array}$} & \multirow{2}{*}{$\begin{array}{c}\begin{array}{c}\text { Perda } \\
\text { Relacional }\end{array} \\
13,91\end{array}$} & \multirow{2}{*}{$\begin{array}{c}\text { Evitamento } \\
7,48\end{array}$} \\
\hline \multirow{13}{*}{$\begin{array}{l}\text { Variáveis } \\
\text { profissionais }\end{array}$} & \multirow{3}{*}{$\begin{array}{l}\text { Unidade funcional de } \\
\text { prestação de cuidados }\end{array}$} & UCC & & & \\
\hline & & USF & 9,60 & 15,00 & 7,62 \\
\hline & & UCSP & 9,78 & 15,92 & 8,03 \\
\hline & \multirow{3}{*}{ Tipo de horário realizado } & Jornada contínua & 9,47 & 14,72 & 7,62 \\
\hline & & Horário rígido & 10,75 & 16,37 & 8,37 \\
\hline & & Horário flexível & 9,50 & 14,75 & 7,75 \\
\hline & \multirow{2}{*}{ Carga horária semanal } & 35 horas semanais & 9,61 & 14,91 & 7,72 \\
\hline & & 40 horas semanais & 8,00 & 12,00 & 6,00 \\
\hline & \multirow{2}{*}{ Cuidador Informal } & Sim & 10,30 & 15,97 & 7,63 \\
\hline & & Não & 9,17 & 14,23 & 7,71 \\
\hline & \multirow{3}{*}{$\begin{array}{l}\text { Motivo para ser cuidador } \\
\text { informal }\end{array}$} & Opção pessoal & 10,50 & 15,54 & 7,50 \\
\hline & & Decisão familiar & 10,09 & 16,63 & 7,90 \\
\hline & & Satisfação pessoal/ Solidariedade & 9,66 & 16,66 & 7,66 \\
\hline
\end{tabular}

Nota . UCC = Unidade de Cuidados na Comunidade; USF = Unidade de Saúde Familiar; UCSP = Unidade de Cuidados de Saúde Personalizados.

\section{Discussáo}

O sofrimento nos enfermeiros é um tema que tem ganho algum destaque nos últimos anos, quer na enfermagem nacional quer na internacional. No presente estudo, e de acordo com a literatura (Schaefer, 2017), a maioria dos participantes sáo do sexo feminino $(90 \%)$, tal como se verifica na profissão de enfermagem, o que se justifica pelos papéis estabelecidos socialmente em relação ao homem e à mulher e ao papel de cuidador na família ter sido tradicionalmente atribuído à mulher.

$\mathrm{Na}$ literatura discute-se se a enfermagem será uma profissão mais predisposta ao sofrimento por ser maioritariamente feminina. Alguns estudos revelam maiores índices de sofrimento no sexo feminino (Trautmann, Epstein, Rovnyak, \& Snyder, 2015) e outros no sexo masculino, mas a maioria não aponta para diferenças significativas entre os sexos (Woods, Rodgers, Towers, \& Grow, 2015; Xiaoyan, Yufang, Lifeng, \& Congcong, 2016). Neste estudo verificou-se que o sexo feminino apresenta médias mais elevadas em todas as dimensóes do sofrimento, com exceção para o sexo feminino sem filhos na dimensão PR e sem companheiro nas dimensões DE e PR. De acordo com Rodrigues e Silva (2016), a fragilidade é entendida como uma característica peculiar das mulheres que sugere feminilidade, pois ainda predomina a lógica da cultura machista em que o homem é potencialmente sexuado, forte e trabalhador, sendo que o trabalho o torna digno e fonte de sustento para a família.

Relativamente ao estado civil, o sexo feminino com companheiro apresenta médias de sofrimento mais elevadas nas dimensões $\mathrm{PR}$ e EV. A dimensão DE é mais expressiva no sexo feminino sem companheiro, o que poderá ser o reflexo da ausência de espaços de partilha. A compreensão da vivência do sofrimento no sexo feminino, mais especificamente nas dimensōes PR e EV, pode ser explicada pela necessidade de proteger a relação com o companheiro, ou seja, não transmitir as situações de sofrimento para a relação conjugal minimizando o efeito do desgaste na mesma.

Apesar da mudança do papel social que a mulher tem vindo a assumir, ainda se verifica que no seio da família continua a liderar as tarefas que contribuem para o bem- estar e a estabilidade familiar protegendo a família das situaçóes de desgaste emocional. Embora a literatura não faça referência à expressão do sofrimento nos enfermeiros em função da existência ou não de filhos, constata-se, no presente estudo, médias ligeiramente mais elevadas em todas as dimensóes do sofrimento no sexo feminino com filhos. Tratando-se de uma profissão maioritariamente feminina e potenciada por uma matriz cultural que sublinha a predisposição maternal para cuidar, os resultados parecem apontar que o sexo feminino apresenta maior sensibilidade e envolvimento nas experiências de sofrimento. Quanto aos enfermeiros do sexo masculino com filhos, verificam-se médias superiores apenas na dimensão EV, o que pode ser justificado pela necessidade de se protegerem da dor psicológica e com o objetivo de não a transferir para o agregado familiar.

No que se refere às variáveis profissionais, constata-se que a formação em enfermagem, quer para a obtenção de graus académicos ou a atribuição de títulos de especialização profissional, tem vindo a contribuir para a aquisição de conhecimentos e competências para uma intervenção profissional especializada. No entanto, devem ser equacionadas estratégias mais eficazes no sentido de garantir uma melhor gestão das situaçóes de sofrimento por parte dos profissionais do sexo masculino. Quanto ao tempo de serviço, de um modo geral verifica-se que os profissionais com mais tempo de exercício profissional apresentam médias de sofrimento mais elevadas, em quase todas as dimensóes. No entanto, Schaefer (2017) 
constatou que os enfermeiros com menos tempo de serviço apresentavam mais sofrimento. No que respeita a estas variáveis, a literatura não é consensual, sendo que alguns estudos apontam relaçóes significativas com a idade e tempo de serviço (Woods et al., 2015), enquanto noutros esta relação não se verifica (Lusignani, Gianni, Re, \& Buffon, 2016).

A maioria dos estudos acerca do sofrimento tem sido realizada em contextos hospitalares, principalmente em serviços de cuidados intensivos e de urgência/emergência (Trautmann et al., 2015). Os enfermeiros que trabalham nestes contextos apresentaram maior sofrimento, quando comparados com os enfermeiros dos CSP (Schaefer, 2017). Neste estudo, constata-se médias de sofrimento mais elevadas nos enfermeiros que nunca têm contacto com situaçóes de urgência/emergência ou prestam cuidados a pessoas em sofrimento, o que pode ser explicado por fatores relacionados com a reforma dos CSP, na qual os enfermeiros têm assumido uma maior participação, autonomia, competências específicas e responsabilidades que poderão ser fontes geradoras de sofrimento $(\mathrm{Ra}-$ mos et al., 2016). Os profissionais de enfermagem que frequentemente transmitem a informação da morte à família/cuidador apresentam médias mais elevadas em todas as dimensóes do sofrimento, o que vai ao encontro da literatura quando refere que ao confrontar-se com o sofrimento e morte, o enfermeiro também sofre, porque toma consciência da sua própria finitude e sente-se impotente face à morte (Viana, 2014).

Relativamente à unidade funcional de prestação de cuidados, os enfermeiros que prestam cuidados nas UCSP apresentam médias mais elevadas em todas as dimensôes de sofrimento, contrariamente aos que prestam cuidados nas UCC, frequentemente a pessoas mais vulneráveis, em sofrimento ou em fase terminal. De facto, as UCSP mantêm um registo de funcionamento que não se alterou com a reforma dos CSP e que tem reflexo nas condiçôes laborais, na afetação de recursos humanos e logísticos, na valorização profissional e na satisfação com o trabalho (Viana, 2014).

Os enfermeiros que têm uma carga horária de 35 horas semanais, que realizam horário rígido e que frequentemente trabalham em jornada contínua com menos elementos que o inicialmente planeado, apresentam médias mais elevadas em todas as dimensóes do sofrimento, o que é corroborado pela literatura ao referir que a prática de horários rígidos e a excessiva carga de trabalho propiciam o sofrimento, conduzindo ao desgaste e alienação profissional (McCarthy \& Gastmans, 2015). Os enfermeiros que, também desempenham o papel de cuidador informal, apresentam médias de sofrimento mais elevadas nas dimensôes $\mathrm{DE}$ e PR, que poderá ser o reflexo da vivência com situações de sofrimento dos seus familiares, do receio de rutura no relacionamento e das experiências partilhadas com a pessoa cuidada. No presente estudo, o papel de cuidador informal é assumido somente por mulheres, o que é corroborado pela literatura ao referir que o papel de cuidador na família é tradicionalmente atribuído à mulher (Coelho \& Ferreira, 2015).

O presente estudo releva a relação das variáveis sociode- mográficas e profissionais no sofrimento dos enfermeiros. Como tal, entende-se que as instituiçóes de saúde devem elaborar estratégias de prevenção e enfrentamento do sofrimento nos ambientes de trabalho, como por exemplo, a criação de espaços de partilha de experiências e reflexão, de modo a contribuir para maior satisfação profissional e pessoal, melhoria da qualidade dos cuidados prestados aos doentes/famílias e comunidade, e consequentemente, maior produtividade e rentabilização de recursos, o que é também sugerido na literatura (Barlem \& Ramos, 2015; McCarthy \& Gastmans, 2015; Schaefer \& Vieira, 2015; Ramos et al., 2016; Caçador et al., 2017; Coelho et al., 2017). Em futuras investigaçôes, seria pertinente estudar também, as consequências do sofrimento no quotidiano pessoal e profissional do enfermeiro, quer seja pela desqualificação do cuidado, ou até mesmo pelo abandono da profissão (Ramos et al., 2016).

\section{Conclusão}

Os enfermeiros em CSP apresentam médias mais elevadas de sofrimento na dimensão $\mathrm{DE}$, seguida da dimensão $\mathrm{PR}$ e por fim na dimensão EV. Só as comparaçóes entre sexos produziram diferenças dignas de registo sendo que o sexo feminino sofre mais do que o sexo masculino.

A compreensão do sofrimento é primordial para a prática de enfermagem e para os gestores das instituiçôes de saúde, na medida em que estes podem adotar uma atitude proativa na implementação de estratégias que visem a melhoria da qualidade de vida destes profissionais, contribuindo para a qualidade e segurança dos cuidados e, consequentemente, ganhos em saúde. Se no presente estudo a avaliação do sofrimento nos enfermeiros privilegiou a relação estabelecida com o doente/família através da CGS, justifica-se a necessidade de, em futuros estudos, introduzir outros fatores de natureza organizacional, no sentido de uma compreensão mais alargada deste fenómeno e monitorização das consequências do sofrimento nos profissionais de enfermagem. $\mathrm{O}$ facto deste estudo envolver apenas enfermeiros de um ACeS do interior Norte de Portugal poderá ter constituído uma limitação, pelo que em futuras investigações se justifica o alargamento do mesmo a outras regiôes do país.

\section{Contribuição de autores}

Conceptualização: Pires, L. M.

Tratamento de dados: Pires, L. M., Monteiro, M. J.

Metodologia: Pires, L. M., Monteiro, M. J., Vasconcelos-Raposo, J.

Redação - preparação do rascunho original: Pires, L. M., Monteiro, M. J.

Redação - revisão e edição: Pires, L. M.

\section{Referências bibliográficas}

Adwan, J. Z. (2014). Pediatric nurses' grief experience, burnout and job satisfaction. Journal of Pediatric Nursing, 29(4), 329-336. doi:10.1016/j.pedn.2014.01.011 
Barlem, E. L., \& Ramos, F. R. (2015). Constructing a theoretical model of moral distress. Nursing Ethics, 22(5), 608-6015. doi: $10.1177 / 0969733014551595$

Caçador, B. S., Ramos, F. R. \& Brito, M. J. (2017). Processo de angústia/sofrimento moral em enfermeiros da estratégia saúde da família. Enfermagem em Foco, 7(3-4), 22-26. doi:10.21675/ 2357-707X.2016.v7.n3/4.910

Coelho, A., Brito, M., \& Barbosa, A. (2017). Caregiver anticipatory grief: Phenomenology, assessment and clinical interventions. Current Opinion in Supportive and Palliative Care, 12(1), 52-57. doi:10.1097/SPC.0000000000000321

Coelho, M. E., \& Ferreira, A. C. (2015). Cuidados paliativos: Narrativas do sofrimento na escuta do outro. Revista Bioética, 2, 340. doi:10.1590/1983-80422015232073

Feneli, R., Gonçalves, T., \& Azevedo dos Santos, S. (2006). A dor e o sofrimento - uma conexão entre o pensar filosófico e espiritual. Enfermeria Global, 9, 1-12. Recuperado de https://digitum.um.es/ digitum/bitstream/10201/24149/3/A\%20dor\%20e\%20o\%20 sofrimento $\% 20-\% 20$ uma $\% 20$ conex $\%$ C3\%A3o\%20entre $\% 20$ o\%20pensar\%20filos\%C3\%B3fico\%20e\%20o\%20espiritual.pdf

Krikorian, A., Limonero, J. T., Román, J. P., Vargas, J. J., \& Palacio, C. (2014). Predictors of suffering in advanced cancer. The American Journal of Hospice \& Palliative Care, 31(5), 534-542. doi: 10.1177/1049909113494092

Lusignani, M., Gianni, M. L., Re, L. G., \& Buffon, M. L. (2016). Moral distress among nurses in medical, surgical and intensive-care units. Journal of Nursing Management, 25(6), 477-485. doi:10.1111/jonm.12431

McCarthy, J., \& Gastmans, C. (2015). Moral distress: a review of the argument-based nursing ethics literature. Nursing Ethics, 22(1), 131-152. doi:10.1177/096973301455713

Meichsner, F., Schinköthe, D., \& Wilz, G. (2016). The caregiver grief scale: Development, exploratory and confirmatory factor analysis, and validation. Clinical Gerontologist, 39(4), 342-361. doi:10.10 80/07317115.2015.1121947

Ramos, F. R., Barth, P. O., Schneider, A. M., Cabral, A. S., Reinaldo, J. S. (2016). Consequências do sofrimento moral em enfermeiros: Revisão integrativa. Cogitare Enfermagem, 21(2), 01-13. Recuperado de https://www.researchgate.net/publication/305313252_CONSEQUENCIAS_DO_SOFRIMENTO_ MORAL_EM_ENFERMEIROS_REVISAO_INTEGRATIVA Regulamento no 128/2011, de 18 de fevereiro. Diário da República, 35/2011-IISérie. Ministério da Saúde. Lisboa, Portugal.

Rodrigues, J. O., \& Silva, E. A. (2016). O prazer e o sofrimento dos homens no trabalho em serviços de saúde. Revista de Enfermagem UFPE on line, 10(7), 2544-2554. doi:10.5205/reuol.9106-802301-SM1007201631

Schaefer, R. (2017). Sofrimento moral: avaliação de risco em enfermeiros (Tese de doutoramento). Universidade Católica Portuguesa, Lisboa. Recuperado de https://repositorio.ucp.pt/bitstream/10400.14/24202/1/PhD_Rafaela\%20Schaefer.pdf

Schaefer, R., \& Vieira, M. (2015). Competência ética como recurso de enfrentamento do sofrimento moral em enfermagem. Texto \& Contexto Enfermagem, 24(2), 563-573. Disponível em http:// www.scielo.br/pdf/tce/v24n2/pt_0104-0707-tce-24-02-00563.pdf

Trautmann, J., Epstein, E., Rovnyak, V., \& Snyder, A. (2015). Relationships among moral distress, level of practice independence, and intent to leave of nurse practitioners in emergency departments: Results from a national survey. Advanced Emergency Nursing Journal, 37(2), 134-145. doi:10.1097/TME.0000000000000060 Vasconcelos-Raposo, J., Pires, L. M., Teixeira, C. M., \& Monteiro, M. J. (no prelo). Validação da Caregiver Grief Scale para enfermeiros. Avaliação Psicológica, 2020.

Viana, A. (2014). Sofrimento experienciado pelo enfermeiro quando cuida o doente em fim de vida com dor não controlada (Dissertação de mestrado). Instituto Politécnico de Viana do Castelo. Recuperado de http://repositorio.ipvc.pt/bitstream/20.500.11960/1237/1/ Aurora_Viana.pdf

Woods, M., Rodgers, V., Towers, A., \& Grow, S. L. (2015). Researching moral distress among New Zealand nurses: A national survey. Nursing Ethics, 22(1), 117-130. doi:10.1177/0969733014542679

Xiaoyan, W., Yufang, Z., Lifeng, C., \& Congcong, S. (2016). Moral disess and its influencing factors: A crossectional study in China. Nursing Ethics, 25(4), 470-480. doi:10.1177/0969733016658792 
